\title{
Radiological risks in the construction and operation of alpine tunnels
}

\author{
M. De Salve ${ }^{1}$, M. Esposito ${ }^{2}$, P. Gozzelino ${ }^{1} \&$ M. E. Parisi ${ }^{3}$ \\ ${ }^{1}$ Department of Energetic, Turin Polytechnic, Italy \\ ${ }^{2} U$-series s.r.l, Italy \\ ${ }^{3}$ LTF SAS
}

\begin{abstract}
The construction of long tunnels for railway transport poses the problem of the evaluation of the environmental impact and the reduction and prevention of risks for the workers and for the population. Important risks are connected with the presence of natural ionizing radiation produced by radionuclides such as Uranium, Thorium, Radon and their daughters. The main pathway of the workers exposure includes both external and internal irradiation risks. LTF (Lyon Turin Ferroviaire SAS) has performed a predictive evaluation of the radiological risk from the analysis of litotypes found during the boreholes. This work is connected with the project for the railway connection between Turin-Lyon and is carried out with the collaboration of Turin Polytechnic, LTF SAS and the U-series laboratory in Bologna. The purpose of this study is the acquisition of the information and data necessary for the evaluation of the radiological risk in the region affected by the works for the railway connection, with particular attention to the areas with workers and/or local people. The results obtained allow us to classify the litotypes for the disposal, to estimate the radioactivity sources, considering the permeation properties, and to carry out an analysis of the correlation between radioactivity concentrations in the litotypes and the water sources influenced by the digging.
\end{abstract}

Keywords: radiological risk, external irradiation, Uranium, Thorium, Radium and Potassium-40.

\section{Introduction}

The Italian territory is bordered in the north by a chain of Alps which needs to be crossed in order to reach other European countries. Therefore, the studies 
regarding the territory (characteristics, structures, naturally occurring elements, and so on) play an important role in planning and designing new communication strategies. The primary objective of the present study is the acquisition of information and data necessary for the forecast of the radiological risk in the region affected by the work for the railway connection. This information on terrestrial radiation and radioactivity is of extreme importance with regards to health.

Considerable attention has been given to possible exposure of humans to ionizing radiation from external and internal environmental sources. Therefore, the determination of radioisotope concentrations in the rocks found during the excavation can supply important data. The main pathway of the workers exposure includes both external and internal irradiation. External irradiation is due to gamma ray emissions from the natural radionuclides present in rocks (Uranium and Thorium families and Potassium-40). Internal irradiation is caused by radon inhalation $\left({ }^{222} \mathrm{Rn}\right.$ and $\left.{ }^{220} \mathrm{Rn}\right)$ and by inhalation of radioactive powders produced during the excavation. Radon is a noble gas which is easily emanated from soil and rocks and can be carried, from ground water, up to a great distance. If the excavation intercepts the ground waters, the radon gas is quickly released into the air posing a significant risk for the workers. It is very important to understand the distribution of the natural radioisotopes in order to classify the quality of the air in the tunnel. Finally, it is important to emphasize that the excavation could alter the flow of the groundwater which could modify its chemical composition because it has flown over different rocks with a different speed. In order to evaluate radiological risks it is very important to focus on Radium because, in ground water, it is a subject of both practical and scientific importance. The practical importance stems from the human health risks associated with both the ingestion of $\mathrm{Ra}$ [1] and the inhalation of $\mathrm{Rn}$ and its daughter products ([1] and [2]). These risks have prompted European and national regulations concerning the maximum total alpha and beta activity concentration in drinking water [3]. The scientific importance derives largely from the potential applications of $\mathrm{Ra}$ isotopes in tracing the mechanisms and rates of water-rock interaction and element transport in aquifers ([4] and [5]). The information from such scientific studies can lead to an improved understanding of the factors controlling water quality and can be useful in establishing better strategies for the use and protection of under-ground water resources.

This study was undertaken to estimate the radiation hazard indices in sedimentary and not rocks from the Val Susa Region and to predict the effective dose received by workers from only external irradiation during underground operations. The evaluation of the global effective dose which workers are exposed to needs to consider inhalation of radon and long-lived radioactive dust and it is the scope of this work.

\section{Radiological risks}

Measurement of natural radioactivity in ground is very important in order to determine the amount of change in the natural background activity which may 
occur over time, as a result of any radioactive release. Monitoring of any release of radioactivity to the environment is important for environmental protection. Radon $\left({ }^{222} \mathrm{Rn}\right)$ is a radioactive noble gas, so an inert gas, (half-life $3.82 \mathrm{~d}$ ) produced naturally by the decay of radium in soils and rocks. It has been hypothesised that ${ }^{222} \mathrm{Rn}$ transfers from bedrock to groundwater via an alpha recoil process followed by diffusion. ${ }^{222} \mathrm{Rn}$ is normally transferred, according to the normal use of water, from water to air by out-gassing, especially if the water is agitated or heated.

All significant exposure pathways need to be considered and these include the following:

- Direct exposure to external radiation from the rock material;

- Internal dose from inhalation of airborne radionuclides, including radon progeny;

- Internal dose from ingestion of drinking water.

The pathway analysis has four parts: (1) source analysis, (2) environmental transport analysis, (3) dose/exposure analysis, and (4) scenario analysis.

Source analysis addresses the problem of deriving the source terms that determine the rate at which radioactivity is released into the environment. This rate is determined by the geometry of the zone, the concentrations of the radionuclides present, the ingrowths and decay rates of the radionuclides, and the removal rate by erosion and leaching.

Environmental transport analysis addresses the problems of identifying environmental pathways by which radionuclides can migrate from the source to a human exposure location and determining the migration rate along these pathways. The gamma-ray radiation hazards which are due to the specified radionuclides $\mathrm{U}, \mathrm{Ra}$, Th and $\mathrm{K}$ were assessed by many different indices, often embedded in national regulations to prevent the use of high radioactive building materials. Some studies about the indices have been done by some authors [6], [7] and [8]. The final index has been suggested to the European Commission [7] for use in future directives. The index is described as follows:

$$
I=\frac{C_{R a}}{300}+\frac{C_{T h}}{200}+\frac{C_{K}}{3000}
$$

where $\mathrm{C}_{\mathrm{Ra}}, \mathrm{C}_{\mathrm{Th}}, \mathrm{C}_{\mathrm{K}}$ are, respectively, in Radium, Thorium and Potassium activity concentrations in $\mathrm{Bq} / \mathrm{kg}$, and the coefficients are the concentrations of the same isotopes, in $\mathrm{Bq} / \mathrm{kg}$, which provide a dose like $1 \mathrm{mSv} / \mathrm{y}$. When the activity index is less than 1 in all materials used for a standard room (dimensions of $5 \times 4 \times 2.7 \mathrm{~m}$, with homogeneous wall 20 centimetres thick, without opening) it is unlikely that the people in this room will receive an exposure in excess of $1 \mathrm{mSv} / \mathrm{y}$. Moreover, when the activity index is less than 0.5 , the material can be used without any restriction to the quantity of the final use of the building. Nevertheless this activity index is not intended for dose evaluation, but only for the safe use of a building material. When applied to the walls of underground cavities, the activity index is an effective way to evaluate the radiological risk for workers. The evaluation of the index I for the mucking during the excavation of tunnels gives a criterium for disposal or final use. The total outdoor air absorbed dose rate, D $(\mathrm{nGy} / \mathrm{h})$ due to the mean activity concentrations of ${ }^{238} \mathrm{U},{ }^{232} \mathrm{Th}$ and ${ }^{40} \mathrm{~K}(\mathrm{~Bq} / \mathrm{kg})$ in 
soils and rocks, is calculated using the formula of Beck et al. [10] and UNSCEAR [11]:

$$
D=0.427 A_{U}+0.622 A_{T h}+0.0432 A_{K}
$$

Beck et al. derived this equation for calculating the absorbed dose rate in air at a height of $1.0 \mathrm{~m}$ above the ground from measured radionuclide concentrations in environmental materials.

The value of the quotient of effective dose equivalent rate to absorbed dose rate in air is 1 for photons [12]. This value applied equally to males and females and to indoor and outdoor environments.

In a working environment like a tunnel the occupancy factor is 1 for 2000 hours/year, the annual effective dose equivalent from terrestrial gamma-radiation is found to be:

$$
D_{a}=2000(h / y) * D(n G y / h) * 1(S v / G y)
$$

\section{Materials and methods}

The underground of Val Susa region has been investigated till $915 \mathrm{~m}$ of depth by drilling. Thirty boreholes have been done to represent the entire Val Susa along the proposed tunnel alignment. All the carrots found (about $7000 \mathrm{~m}$ in depth) have been classified in 12 main litotype groups cited in table 1 .

Table 1: $\quad$ Litotype groups found in Val Susa.

\begin{tabular}{|c|c|c|}
\hline Litotype groups & length & \% \\
\hline & {$[\mathrm{m}]$} & \\
\hline Calcareous schist & 2049.4 & 29.17 \\
\hline Gneiss & 1126.45 & 16.03 \\
\hline Mica schist & 801.90 & 11.41 \\
\hline Detrital deposit & 585.5 & 8.33 \\
\hline Schist & 384.00 & 5.46 \\
\hline Marble & 440.80 & 6.27 \\
\hline Serpentine & 131.10 & 1.87 \\
\hline Prasinite & 78.55 & 1.12 \\
\hline Quartzite & 77.25 & 1.10 \\
\hline Dolomite & 88.20 & 1.25 \\
\hline Mylonite & 12.80 & 0.18 \\
\hline Limestone & 11.70 & 0.17 \\
\hline
\end{tabular}

The object of the study is the choice of a representative number of samples to characterize, at best, the natural radioactivity present in the rocks found in the area. Fifty samples belonging to litotypes mentioned in table 1 (three for every main group and one for every secondary) have been chosen and measured by gamma-ray spectroscopic analysis. The samples are collected in their natural form and ground to fine powder, dried and sealed in cylindrical polyethylene containers of $5.5 \mathrm{~cm}$ diameter and $11 \mathrm{~mm}$ height. The spectrometer consists of 3 HPGe p-type (relative efficiency $10 \%, 20 \%$ and 30\%) coupled with 16384 
multicanale. The ${ }^{238} \mathrm{U}$ activity was measured from the ${ }^{234} \mathrm{Th}$ gamma ray at 63.4 $\mathrm{KeV}$, the ${ }^{226} \mathrm{Ra}$ activities were estimated from ${ }^{214} \mathrm{~Pb}(295.2,351.9 \mathrm{keV})$ and ${ }^{214} \mathrm{Bi}$ $(609.3,1120.3 \mathrm{keV})$. The gamma-ray energies of ${ }^{212} \mathrm{~Pb}(238.6 \mathrm{keV}),{ }^{228} \mathrm{Ac}$ $(338.4,911 \mathrm{keV})$ and ${ }^{208} \mathrm{Tl}(583.2 \mathrm{keV})$ were used to measure the concentration of $232 \mathrm{Th}$, while the ${ }^{40} \mathrm{~K}$ activity was determined from the $1460.7 \mathrm{keV}$ emission. Measurements were conducted following Italian standards UNI 10797 [13].

\section{Results and discussion}

Table 2 shows the activities in $\mathrm{Bq} / \mathrm{kg}$ obtained from the gamma-ray spectroscopic analysis and estimated doses $\mathrm{D}$ and $\mathrm{D}_{\mathrm{a}}$.

Results indicate that the area under investigation has a normal level of natural background. Also, ${ }^{40} \mathrm{~K}$ shows high concentration but still within the natural background level values. These values are considered to be at a typical level for the ground samples from this area. Figure 1 shows the values found for the activity radiological index.

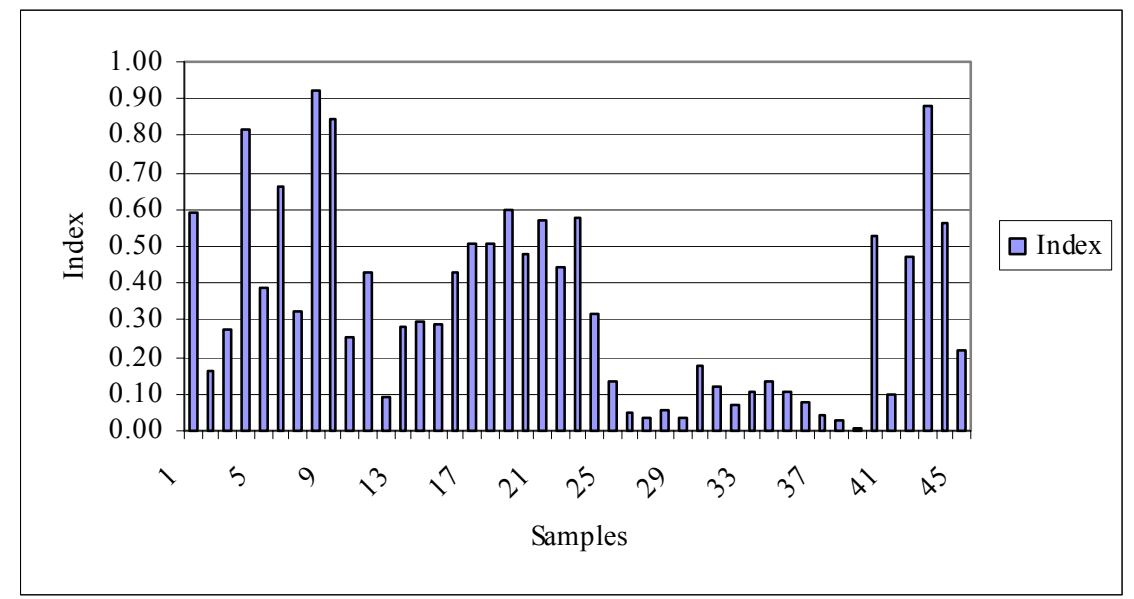

Figure 1: Activity radiological index.

In figure 1, the numbers represent the samples shown in table 2 where the reference litotype and activity are reported.

All the samples have a radioactivity index less than 1 . The starting safety conditions of excavation activities should be good for the workers. The annual effective dose equivalent calculated reaches $0,2 \mathrm{mSv} / \mathrm{y},<1 \mathrm{mSv} / \mathrm{y}$ Italian normative limit [12] for the workers who are not at risk, but it is important if we consider that the external irradiation is negligible compared with the internal irradiation caused by radon and radioactive powders inhalation.

Therefore, the workers should be exposed to a dose more than $1 \mathrm{mSv} / \mathrm{y}$ with non-sufficient mechanical ventilation and lowering powder concentration. Further studies on Radon emanation from rocks and groundwater in the area 
concerned with the tunnel, can help to calculate the radiological risks during the excavation activities.

Table 2: $\quad$ Results obtained from gamma-ray spectroscopic analysis and using the eqns. (2) and (3).

\begin{tabular}{|c|c|c|c|c|c|c|c|c|c|c|c|c|c|c|c|}
\hline $\mathbf{N}^{\circ}$ & Litotype & \multicolumn{3}{|c|}{ U-238 } & \multicolumn{3}{|c|}{ Ra-226 } & \multicolumn{3}{|c|}{ Th-232 } & \multicolumn{3}{|c|}{ K-40 } & D & $\mathbf{D}_{\mathbf{a}}$ \\
\hline & & \multicolumn{3}{|c|}{$[\mathrm{Bq} / \mathbf{k g}]$} & \multicolumn{3}{|c|}{$[\mathrm{Bq} / \mathbf{k g}]$} & \multicolumn{3}{|c|}{$[\mathrm{Bq} / \mathbf{k g}]$} & \multicolumn{3}{|c|}{$[\mathrm{Bq} / \mathbf{k g}]$} & {$[\mathrm{nGy} / \mathrm{h}]$} & {$[\mathrm{mSv} / \mathbf{y}]$} \\
\hline 1 & \multirow{9}{*}{ Gneiss } & 40 & \pm & 30 & 19 & \pm & 4 & 34 & \pm & 5 & 1080 & \pm & 130 & 84.88 & 0.170 \\
\hline 2 & & 15 & \pm & 6 & 16.2 & \pm & 1.5 & 7.0 & \pm & 1.7 & 210 & \pm & 20 & 19.83 & 0.040 \\
\hline 3 & & 20 & \pm & 7 & 21 & \pm & 4 & 12.9 & \pm & 0.8 & 430 & \pm & 40 & 35.14 & 0.070 \\
\hline 4 & & 34 & \pm & 12 & 55 & \pm & 7 & 85 & \pm & 6 & 630 & \pm & 50 & 94.60 & 0.189 \\
\hline 5 & & 25 & \pm & 8 & 23 & \pm & 3 & 26 & \pm & 3 & 550 & \pm & 50 & 50.61 & 0.101 \\
\hline 6 & & 60 & \pm & 30 & 35 & \pm & 4 & 50 & \pm & 3 & 890 & \pm & 110 & 95.17 & 0.190 \\
\hline 7 & & 33 & \pm & 17 & 17 & \pm & 2 & 28 & \pm & 2 & 390 & \pm & 50 & 48.36 & 0.097 \\
\hline 8 & & 70 & \pm & 40 & 58 & \pm & 4 & 76 & \pm & 6 & 1040 & \pm & 120 & 122.09 & 0.244 \\
\hline 9 & & 50 & \pm & 8 & 50 & \pm & 8 & 50 & \pm & 2 & 1280 & \pm & 150 & 107.75 & 0.215 \\
\hline 10 & \multirow{7}{*}{$\begin{array}{l}\text { detrital } \\
\text { deposit }\end{array}$} & 15 & \pm & 6 & 18 & \pm & 2 & 20 & \pm & 3 & 280 & \pm & 30 & 40.12 & 0.080 \\
\hline 11 & & 26 & \pm & 4 & 26 & \pm & 4 & 29 & \pm & 6 & 600 & \pm & 70 & 37.59 & 0.075 \\
\hline 12 & & 6.8 & \pm & 1.7 & 6.8 & \pm & 1.7 & 4.4 & \pm & 0.7 & 133 & \pm & 19 & 30.94 & 0.062 \\
\hline 13 & & 31 & \pm & 13 & 20 & \pm & 5 & 21 & \pm & 2 & 320 & \pm & 40 & 55.06 & 0.110 \\
\hline 14 & & 20 & \pm & 4 & 20 & \pm & 4 & 22 & \pm & 2 & 360 & \pm & 40 & 11.39 & 0.023 \\
\hline 15 & & 13 & \pm & 6 & 13 & \pm & 6 & 12 & \pm & 3 & 560 & \pm & 70 & 37.21 & 0.074 \\
\hline 16 & & 30 & \pm & 5 & 30 & \pm & 5 & 31 & \pm & 3 & 520 & \pm & 70 & 54.56 & 0.109 \\
\hline 17 & \multirow{7}{*}{ Mica schist } & 26 & \pm & 5 & 26 & \pm & 5 & 30 & \pm & 5 & 820 & \pm & 100 & 65.19 & 0.130 \\
\hline 18 & & 23 & \pm & 8 & 29 & \pm & 4 & 34 & \pm & 2 & 720 & \pm & 60 & 62.07 & 0.124 \\
\hline 19 & & 31 & \pm & 6 & 31 & \pm & 6 & 34 & \pm & 6 & 980 & \pm & 120 & 76.72 & 0.153 \\
\hline 20 & & 30 & \pm & 9 & 27.7 & \pm & 0.9 & 34 & \pm & 2 & 660 & \pm & 50 & 62.47 & 0.125 \\
\hline 21 & & 34 & \pm & 10 & 35 & \pm & 4 & 40 & \pm & 2 & 760 & \pm & 60 & 72.23 & 0.144 \\
\hline 22 & & 17 & \pm & 7 & 22 & \pm & 4 & 27 & \pm & 2 & 710 & \pm & 60 & 54.73 & 0.109 \\
\hline 23 & & 29 & \pm & 4 & 29 & \pm & 4 & 36 & \pm & 2 & 910 & \pm & 110 & 74.09 & 0.148 \\
\hline 24 & \multirow{7}{*}{ Marble } & 32 & \pm & 9 & 33 & \pm & 3 & 28.8 & \pm & 0.9 & 188 & \pm & 18 & 39.70 & 0.079 \\
\hline 25 & & 9 & \pm & 5 & 16.4 & \pm & 1.6 & 5 & \pm & 2 & 168 & \pm & 16 & 14.21 & 0.028 \\
\hline 26 & & 9 & \pm & 4 & 11 & \pm & 2 & & $<1,4$ & & & $<9$ & & 5.10 & 0.010 \\
\hline 27 & & \multicolumn{3}{|c|}{$<4$} & 5.4 & \pm & 0.9 & \multicolumn{3}{|c|}{$<1,4$} & 38 & \pm & 6 & 2.51 & 0.005 \\
\hline 28 & & 12 & \pm & 5 & 14 & \pm & 3 & 1.1 & \pm & 0.2 & & $<9$ & & 6.20 & 0.012 \\
\hline 29 & & 5 & \pm & 2 & 6.7 & \pm & 1.2 & 1.1 & \pm & 0.4 & 24 & \pm & 4 & 3.86 & 0.008 \\
\hline 30 & & \multicolumn{3}{|c|}{$<50$} & 48 & \pm & 8 & 2.4 & \pm & 0.7 & 13 & \pm & 4 & 2.05 & 0.004 \\
\hline 31 & \multirow{3}{*}{ Prasinite } & \multirow{2}{*}{\multicolumn{3}{|c|}{$\begin{array}{l}<7 \\
<7\end{array}$}} & 3.6 & \pm & 1.3 & 1.6 & \pm & 0.4 & 300 & \pm & 20 & 13.96 & 0.028 \\
\hline 32 & & & & & 5 & \pm & 2 & 3 & \pm & 2 & 117 & \pm & 13 & 6.92 & 0.014 \\
\hline 33 & & \multicolumn{3}{|c|}{$<17$} & & $<7$ & & 2.4 & \pm & 0.7 & 210 & \pm & 30 & 10.56 & 0.021 \\
\hline 34 & & & $<40$ & & 10 & \pm & 4 & 9 & \pm & 2 & 160 & \pm & 20 & 12.51 & 0.025 \\
\hline 35 & Calcareous & 25 & \pm & 13 & 8.0 & \pm & 1.7 & 4 & \pm & 3 & 170 & \pm & 20 & 20.51 & 0.041 \\
\hline 36 & & 6 & \pm & 3 & 8.4 & \pm & 1.9 & 8.72 & \pm & 0.14 & 26 & \pm & 4 & 9.11 & 0.018 \\
\hline 37 & & & $<30$ & & & $<5$ & & & $<4$ & & 10 & \pm & 5 & 2.92 & 0.006 \\
\hline 38 & Serpentinite & & n.r. & & & $<3$ & & & $<3$ & & & n.r. & & 1.87 & 0.004 \\
\hline 39 & & & n.r. & & & $<2$ & & & $\overline{<0,6}$ & & & n.r. & & 0.37 & 0.001 \\
\hline 40 & & 50 & \pm & 30 & 31 & \pm & 7 & 34.0 & \pm & 1.5 & 760 & \pm & 90 & 75.33 & 0.151 \\
\hline 41 & Cshist & & $<30$ & & 7.1 & \pm & 1.3 & 10.8 年 & \pm & 1.2 & 61 & \pm & 11 & 9.35 & 0.019 \\
\hline 42 & & 40 & \pm & 19 & 23.0 & \pm & 2.0 & 26.8 & \pm & 1.3 & 790 & \pm & 90 & 67.88 & 0.136 \\
\hline 43 & Ou & 90 & \pm & 50 & 87 & \pm & 13 & 87 & \pm & 12 & 460 & \pm & 60 & 112.42 & 0.225 \\
\hline 44 & Quartzite & 21 & \pm & 6 & 23.4 & \pm & 1.3 & 33 & \pm & 6 & 970 & \pm & 80 & 71.40 & 0.143 \\
\hline 45 & Quartz & 19 & \pm & 7 & 21 & \pm & 5 & 28.0 & \pm & 1.5 & 33 & \pm & 8 & 26.95 & 0.054 \\
\hline
\end{tabular}


This result shows no problem about the radiological risk in the disposal or the final use of the mucking for the known litotype.

\section{Acknowledgements}

This work was supported from LTF sas in the framework of collaboration of department of Geo-resources and land, Turin Polytechnic (Prof. M. Patrucco).

\section{References}

[1] National Academic of Science (NAS), Health Risks of Radon and Other Internally Deposited Alpha Emitters. National Academy Press, Washington, DC, 1988.

[2] NAS/NRC, Health Effects of Exposure to Radon. National Academy Press, Washington, DC, 1998.

[3] DLgs n 31 del 2/2/2001.

[4] Dickson, B.L., Radium in ground water. In: The Environmental Behavior of Radium, vol. 1 (Chapter. 4-2) International Atomic Energy Agency (IAEA), Vienna, pp. 335 $\pm 372,1990$.

[5] Ivanovich, M. \& Harmon, R.S., Uranium-Series Disequilibrium: Applications to Earth, Marine, and Environmental Sciences, 2nd ed. Clarendon Press, pp. 631 $\pm 668,1982$.

[6] Abbady, A.G.E., Estimation of radiation hazard indices from sedimentary rocks in Upper Egypt, Applied Radiation and Isotopes, 60, 111-114, 2004.

[7] Sroora, A., El-Bahia, S.M., Ahmedb, F. \& Abdel-Haleemc, A.S., Natural radioactivity and radon exhalation rate of soil in southern Egypt, Applied Radiation and Isotopes, 55, 873-879, 2001.

[8] Bossew, P., The radon emanation power of building materials, soils and rocks, Applied Radiation and Isotopes, 59, 389-392, 2003.

[9] Directorate-General Environment, Nuclear Safety and Civil Protection, European Commission, Radiological Protection Principles concerning the Natural Radioactivity of Building Materials, Radiation protection 112, 1999.

[10] Beck, H.L., Decompo, J. \& Golgogak, J., In-situ Ge(Li) and $\mathrm{Na}(\mathrm{Tl})$ gamma ray spectrometry. Health and Safety Laboratory AEC (HASL), Report 258, New York, 1972.

[11] United Nations Scientific Committee on the Effects of Atomic Radiation Ionizing Radiation (UNSCEAR): Sources, Effects and Risks of Ionizing Radiation. United Nations, New York, Annex A, B, 1988.

[12] DLgs n ${ }^{\circ} 230$ del 17/03/1995 modified by DLgs n 241 del 26/05/2000.

[13] UNI 10797, Natural radionuclides in the building materialsDetermination with gamma spectrometry - high resolution, 1999. 